\title{
TÉCNICAS DE MODELAGENS E RENDERIZAÇÃO EM SOFTWARES TRIDIMENSIONAIS
}

\author{
Walter Dutra da Silveira Neto \\ Palavras-chave: Técnicas, Modelagem 3D, Render
}

\section{RESUMO}

O presente trabalho teve por objetivo estudar e apresentar as diversas etapas, onde os profissionais que utilizam os softwares tridimensionais devem conhecer para que seu trabalho de modelagem, como também sua renderização final possua aspectos realísticos, como: técnicas de modelagens básicas e especiais, iluminação, texturas e renderização.

\section{Introdução}

Mesmo verificando no final da década de 1960, a conquista de gráficos tridimensionais (3D) com faces coloridas e a emergência de superfícies curvas para a descrição de formas complexas, que efetivamente implicam com técnicas de iluminação e textura, na apresentação de imagens realistas, a façanha de promover o realismo explícito, tanto pelo aperfeiçoamento das técnicas existentes, quanto pelo oferecimento de novos e surpreendentes métodos, deve ser creditada a década de 1970. E quando um dos mais destacados cientistas do período, o norte-americano James Clark (criador da empresa SGI-Silicon Graphic Incorporated, empresa especializada em equipamentos para computação gráfica, empresa esta que liderou a criação da biblioteca OpenGL ${ }^{1}$ e a especificação da linguagem de descrição de cenas de realidade virtual para a Internet $\mathrm{VRML}^{2}$ ), dizia que a busca do realismo por meio do aprimoramento de algoritmos ${ }^{3}$ seria a motivação das pesquisas em computação gráfica, então ficava evidente a distinção entre os objetivos da ciência/tecnologia e aqueles que a arte almejava. Há muito tempo à arte já dispunha de recursos técnicos que lhe permitiam a abordagem do real (em sintonia com um ideal expressivo), e há mais tempo ainda a arte já desfrutava de sua condição intermediadora entre o homem e o mundo - a "magia" que lhe dá sentido.

1. Linguagem gráfica de 3D desenvolvida pela Silicon Graphics. Há duas versões: Cosmo OpenmGL, que roda estações de trabalho da própria Silicon, e Microdoft OpenGL, adaptada para plataformas Windows.

2-Virtual Reality Modeling Language. Padrão para criar ambientes $3 \mathrm{D}$, pelos quais o usuário poderá navegar usando um browser (programas usados para visualizar páginas Web) que suporte o padrão.
Sendo o primeiro passo para a simulação da imagem computadorizada, a etapa de modelagem trazia uma série de desafios. Possivelmente, o maior deles estava em permitir a manipulação de dados geométricos de forma interativa, num procedimento fácil para o usuário, com resposta instantânea, o grande desafio para projetistas e programadores de softwares era trabalhar com computadores da mesma forma que escultores com argila. Mesmo no estágio tecnológico da época, imaginar o contrário era ir contra as evidências da própria natureza, Newman, ainda nos anos 1960, apresentava como principal desvantagem da entrada numérica via teclado, a impossibilidade de conseguir variações contínuas de parâmetros, comparando com meios gráficos como um cursor acionado por trackball ${ }^{4}$. Esse problema também tinha relação com perda de tempo e distração, já que o usuário tinha a atenção da tela a todo o momento.

Em 1976, James Clark ia mais longe, chegando a considerar impróprio o fato de o artista manipular gráficos tridimensionais através de uma interface bidimensional, o que leva o indivíduo a lidar com informações que comprometem o processo, como coordenadas de pontos de superfície ou orientação dos eixos do sistema. O escultor digital é obrigado a entender conceitos que seriam completamente dispensados, caso ele pudesse trabalhar imerso num ambiente virtual tridimensional.

Deficiências técnicas envolvendo hardware e software naturalmente impediam que fosse permitida tal facilidade. Apesar do reconhecimento daqueles pesquisadores interessados em obter métodos análogos ao escultor trabalhando com argila, essa condição impunha requerimentos de softwares extremamente complexos.

3 - Trata-se de um conceito na área de computação que significa uma sequiência finita de passos lógicos e bem definidos para resolver um problema.

DAPesquisa, Florianópolis, v.2, n.4, p. 388-402, 2007. 
Devido a descrição matemática de linhas retas não constituir maiores problemas de implementação no computador, a geometria baseada em polígonos converteu-se na opção padrão para a configuração de superfícies de modelos 3D.

Uma vantagem desse tipo de geometria é a quantidade de tipos de superfície que podem ser definidos, sendo ideal para modelagem de forma que não sofram deformações, caso de edifícios. Por outro lado, formas orgânicas, curvas, são problemáticas com polígonos. Uma esfera formada por uma malha de polígonos pode apresentar uma superfície homogênea, mas o número elevado desse tipo de geometria requer muita memória, além de dificultar a manipulação individual de vértices.

A solução estava em trabalhar no computador diretamente com curvas, o que implicava a descoberta de modelos matemáticos mais refinados. Lançando mão de expressões algébricas polinomiais (equações paramétricas), diversos tipos de curva (chamadas spline, como é conhecida a régua flexível usada por desenhistas) puderam ser especificadas. Com poucas splines integradas, uma superfície curva suave, denominada fragmento (do inglês, patch), podia ser obtida. As arestas curvas do fragmento permitiam deformações matematicamente controladas, perfeitamente suaves adequadas para construir modelos orgânicos complexos, como animais.

Nos anos 1970, vão aparecer vários algoritmos para obtenção de splines, alguns conhecidos pelo nome de quem os desenvolveu, como já acontecera com o Coons patch, nos anos 1960. Podemos citar as Bezier curve, Hermite curve, B-Spline, Cardeal, etc.

O que vai diferenciar o emprego dessas curvas é o modo como cada uma é manipulada por seus pontos de controle.

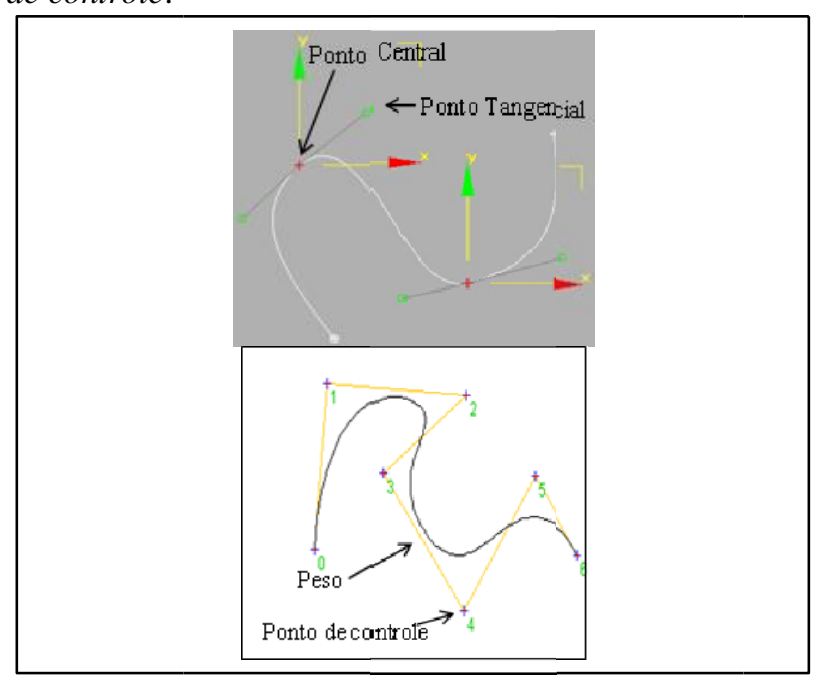

Figura 1 - Curva Bezier Figura 2 - Curva B-spline

\footnotetext{
4 - Dispositivo de indicação semelhante ao mouse
}

É importante registrar que uma das propriedades desejadas da representação matemática de splines é que o artista seja capaz de facilmente controlar a forma do objeto simplesmente movendo pontos de controle, cujas posições afetam a curva, intuitivamente - exatamente como se faz com a régua flexível real.

Uma tese de doutorado defendida na Universidade de Utah, por Edwin Catmull, em 1974 (A Subdivision Algorithm for Computer Display of Curved Surfaces), incrementou o uso de fragmentos bicúbicos para modelagem de superfícies curvas. $\mathrm{O}$ método proposto, como sugere o título da tese, parte para a subdivisão do fragmento, obtendo uma superfície bastante flexível e suave. $\quad \mathrm{O}$ algoritmo induz a subdivisão do fragmento até que cada subfragmento coincida com um pixel ${ }^{5}$.
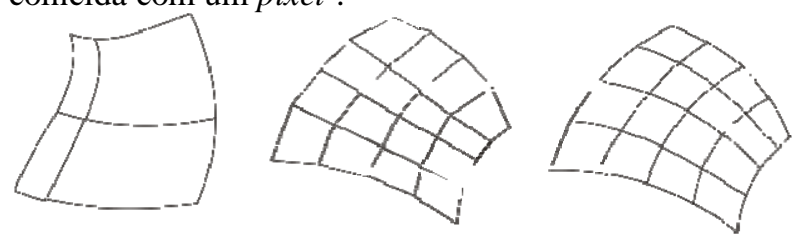

Figura 3 - Subdivisão do fragmento bicúbico

$\mathrm{O}$ artifício que permitiu a Catmull essa alternativa foi sua idéia de utilizar o frame buffer (memória de imagem) para armazenar as informações de profundidade dos valores do eixo $z$ do objeto enquanto no espaço da imagem (uma área intermediária entre o espaço tridimensional e a exibição em perspectiva na tela, que preserva a memória de profundidade). Comparando-se os valores de $z$, aqueles mais próximos do observador seriam conservados, descartando-se os demais.

O z-buffer, como ficou conhecida essa técnica, retinha ainda informações de luminosidade de cada minúsculo fragmento associado ao pixel. Isso trouxe como consequiência a maravilhosa possibilidade de mapear as superfícies dos objetos 3D com desenhos e fotografias, podendo simular texturas realistas.

É a menor parte de uma imagem digitalizada. Cada um destes pontos possui a informação que determina sua cor. Este conjunto de pontos é arrumado no formato de uma matriz. Essa matriz forma a imagem. O pixel determina a resolução desta imagem.

Se polígonos e fragmentos cur os bastavam para modelar formas bem delimitadas, uma variedade de fenômenos, substâncias e objetos existentes, como:

fumaça, fogo, nuvens, plantas, relevos montanhosos, etc., ainda eram um desafio para que se chegasse a uma solução razoável de simulação em 3D. 
Na segunda metade dos anos 1970, o matemático polonês Benoit Mandelbrot formalizou o conceito de fractal $^{\mathbf{6}}$. A dimensão fractal introduzida por Mandelbrot era o recurso que permitia medir propriedades irregulares. Na prática, essa recorrência se valia da característica de auto-semelhança, uma simetria através das escalas - o pequeno se parece com o grande, um padrão dentro de outro padrão. A geometria fractal liberava as formas escondidas na lógica e precisão com que os computadores tratavam à informação.

A geometria fractal é multidimensional. Não a encontramos no espaço euclidiano ${ }^{7}$, mas entre algum ponto entre a primeira e a segunda dimensão, ou entre a segunda e a terceira, de maneira que, em termos matemáticos, é representada por números fracionários. É exatamente esta propriedade que a afasta das dimensões rigorosas da linha, do plano e do volume, que nos permite a liberdade de modelar o universo imprevisível e infinitamente variável. Para tanto, um fator aleatório está presente no algoritmo gerador do fractal, que, mais uma vez, faz uso da idéia de subdivisão recursiva para obtenção de um modelo.

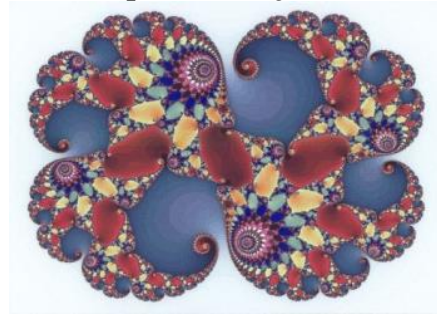

Figura 4 - Fractais

Como se percebe, a técnica é poderosa. Sua eficiência vai estimular o surgimento de outras estratégias para lidar com formas complexas, como o sistema de partículas e as imagens obtidas por graftal $^{8}$.

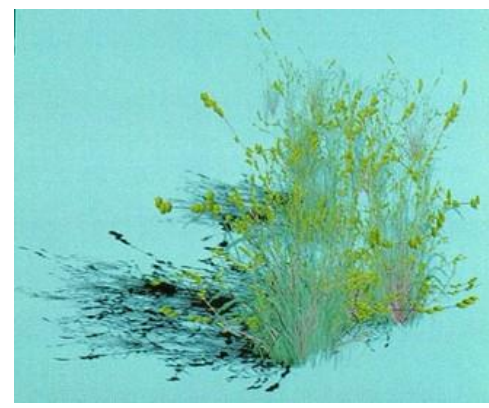

Figura 5 - Graftal

\footnotetext{
${ }^{6}$ - Fractais são figuras da geometria não-Euclidiana, do latim (fractus: fraturar, fracionar)

7 - O espaço de três dimensões.

8 - É uma estrutura abstrata usada em gráficos computacionais que serve para definir recursividade, é utilizada para definir pelos, plantas e etc.
}

Após várias criações de algoritmos voltados para modelagem computacional em $3 \mathrm{D}$, também se tinha de ir testando algoritmos que simulavam processos de modelagem mecânica e desenho técnico encontrados no mundo real, já que era mais fácil adaptá-los ao funcionamento rigoroso do computador e atendiam exatamente ao mercado industrial. Era o caso do uso de tornos, fresadoras, furadeiras, compasso, réguas, etc., instrumentos convenientes à obtenção de um procedimento similar digital. Uma metodologia que se encontra no extremo oposto do desenho expressivo apesar desse lançar mão de formas simples geométricas como base estrutural.

Além do teclado, na década de 1970, encontramos uma vasta gama de dispositivos que permitem a digitalização e/ou manipulação de informação 3D: mesa digitalizadora, joystick, mouse, botões, capacete de visão estereoscópica, luva de dados e outros equipamentos especiais. Apesar das pesquisas com digitalização de modelos físicos através de fotografia, varredura a laser, caneta óptica, além de outras alternativas que ainda encontram-se em aperfeiçoamento, interessam-nos os métodos que permitem ao usuário criar seu modelo 3D a partir de sua própria definição.

Desde o começo existiu uma tendência rumo à especialização dos programas de modelagem, atendendo especificidades profissionais e que ainda são aperfeiçoadas nas novas versões de softwares voltados à modelagem.

\section{Metodologia}

Foi realizado uma pesquisa sobre as técnicas fundamentais utilizada pelos softwares de modelagem tridimensional, bem como, os processos modernos de criação de objetos nesses ambientes. Os princípios básicos de modelagem foram identificados, observados e testados. O objeto de estudo foi definido como o universo da modelagem tridimensional, em virtude de seu uso extremamente difuso no design. Definiu-se que os softwares utilizados para testar tais princípios seriam: 3D Studio Max (Discreet), o Maya (Alias Systems) e o SolidWorks (SolidWorks Co.) em razão da compatibilidade com os sistemas disponíveis, como também da grande versatilidade dos mesmos.

\section{Técnicas Utilizadas}

\subsection{Modelagem}

Para o desenvolvimento de um projeto em modelagem utilizando softwares tridimensionais, diversos métodos são utilizados. Cada técnica de modelagem possui características que podem facilitar na construção de uma determinada geometria. 
Atualmente, os métodos de modelagem oferecidos pela maior parte dos softwares de modelagem tridimensional, de acordo com Lucena (2002), podem ser divididos em cinco categorias:

1. Formas primitivas

2. Modelagem de Forma Livre

3. Geometria Sólida Construtiva, ou CGS ${ }^{9}$

4. Modelagem por procedimento

5. Modelagem por derivação

As primitivas geométricas constituem uma coleção de formas pré-construídas, que possuem diversos parâmetros de configuração formal. São formas padronizadas, de fácil definição matemática, compostas por polígonos ou fragmentos curvos, apresentadas em três e duas dimensões. As geometrias mais comuns são: a esfera, o cubo, o cilindro e o cone, porém, cada software pode oferecer sua diversidade de primitivas.
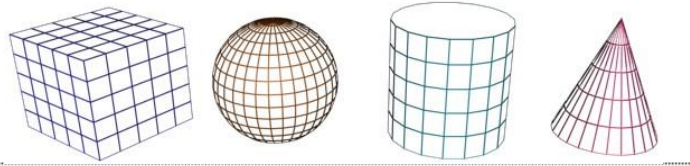

Figura 6 - Formas primitivas.

Partindo desse ponto, podem ser construídas formas complexas combinando as peças pré-moldadas, acionando-as diretamente por meio do mouse ou da caneta eletrônica.

Além de poder movimentar as peças no espaço tridimensional (translação) ou em relação ao seu próprio eixo (rotação), os programas oferecem uma variedade de ferramentas que permitem duplicar os objetos, cortar, torcer, esticar, espelhar, de maneira que procuram simular as operações exercidas por um escultor no mundo real.
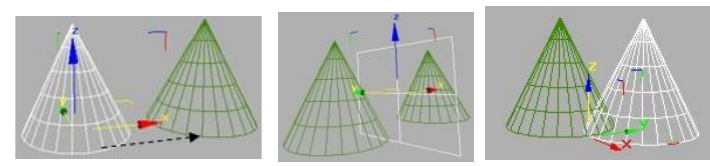

Figura 7 - Translação, reflexão(espelho) e rotação

As possibilidades de manipulação da geometria através de pontos de controle de suas curvas, caracterizam a Modelagem de Forma Livre, uma vez que permite ao usuário trabalhar com pontos isolados da malha ou em conjunto desses pontos.

Esse tipo de modelagem é ideal para modelar superfícies curvas, mas o método era bastante demorado, pois estava associada à rapidez do sistema, alguns softwares como o $3 d s$ Max e o Maya,

\footnotetext{
${ }^{9}$ A “CGS" é um termo utilizado para a modelagem de sólidos, que define complexos sólidos pela composição de sólidos simples (primitivas) e/ou objetos já combinados, até que se chegue a um objeto mais complexo.
}

DAPesquisa, Florianópolis, v.2, n.4, p. 388-402, 2007. aperfeiçoaram muito essa técnica, chamada por alguns profissionais como edição poligonal, baseado na subdivisão de superfícies, o que hoje é bastante utilizadas pelos usuários de softwares $3 \mathrm{~d}$.

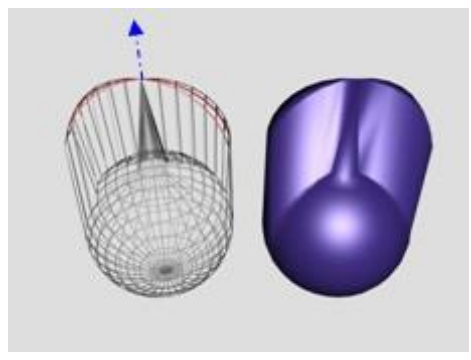

Figura 8 - Manipulação de pontos de controle.

Outra forma de modelagem, a de Geometria Sólida Construtiva $(C S G)$, faz uso de operações de união, intersecção e diferença entre duas geometrias, para a geração de novas formas tridimensionais, chamadas de operações booleanas, pois se baseiam na lógica matemática desenvolvida por George Boole. A partir da aplicação de simples operadores (e, ou, não) como de suas respectivas operações, o usuário pode obter novas formas que, de outra maneira, apresentariam maior dificuldade.
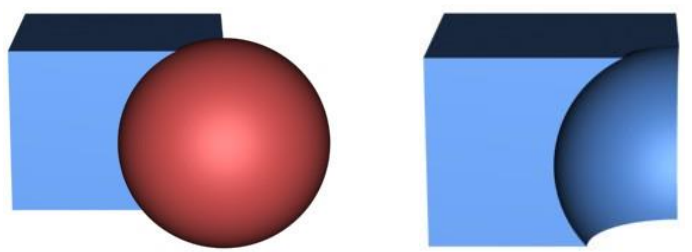

Figura 9 - Operações booleanas

A modelagem por procedimento, faz uso de um determinado algoritmo, não para definir exatamente a geometria de um objeto, mas para atribuir um tipo de procedimento, ou ação, que irá definir como um objeto será gerado. Para o procedimento utilizado, pode-se ter diversos parâmetros a serem configurados, o que possibilita uma facilidade de modificação das características formais do objeto.

Segundo Barbosa Júnior(2002), esse método se baseia na noção de que a informação pode ser gerada por um processo dinâmico não-linear sempre que se queira, em oposição à mera recuperação passiva de dados. No caso de uma imagem, um algoritmo especifica, em termos gerais, como um certo objeto deve ser definido, deixando que certos valores (parâmetros) permaneçam abertos para serem introduzidos posteriormente, à medida que se queira introduzir versões individualizadas do objeto, ou seja, a geometria do objeto não é definida explicitamente, mas representada como um procedimento com o qual interagem, posteriormente, sempre que seja requerido, os argumentos ou variáveis paramétricas adotadas pelo usuário. 
Essa flexibilidade da modelagem por procedimento mostra todo seu poder quando se trabalha com características de modelagem que se modificam com freqüência. Por exemplo, o modelo de uma esfera é gerado pelo fornecimento de sua posição e raio como parâmetros; seus limites são desenhados automaticamente pela fórmula embutida no procedimento. A esfera não é um objeto predefinido, mas é criada sempre que necessário, na resolução que for preciso. Numa cena composta por muitas esferas e havendo a necessidade de proceder a mudanças no modelo, em vez de alterar as características individualmente, bastaria mexer no procedimento para fazer as atualizações requeridas.

Resumindo, a descrição de um modelo por procedimento não trata de esculpir geometricamente, mas, antes, definir seu comportamento. Alterando simplesmente as regras desse comportamento, ativa-se uma cadeia complexa de transformações generalizadas, praticamente impossível de criar por outras técnicas de modelagem digital. Como por exemplo, poderíamos definir o sistema de partículas, que permite definir diversos parâmetros e que estes serão aplicados a vários objetos ao mesmo tempo, observe o exemplo:

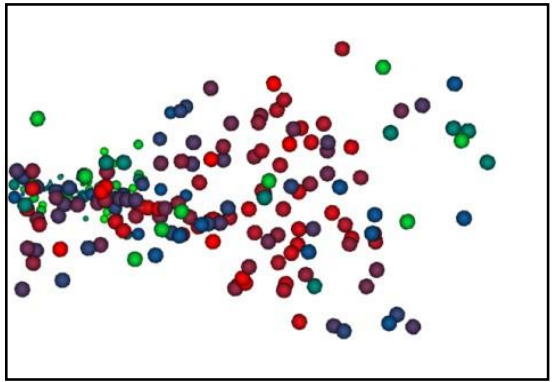

Figura 10 - Modelagem por Procedimento

O método de modelagem por derivação, pode ser subdividido em três outras formas de geração de modelos tridimensionais, porém todas realizam relações entre duas ou mais formas bidimensionais para a criação de um objeto 3D:

- Extrusão

- Secção transversal serial

- Revolução

O método de extrusão permite que uma cópia da forma bidimensional seja estendida ao longo de um eixo espacial selecionado, o termo extrusão vem do uso industrial de moldes através dos quais é forçada a matéria-prima que assim adquiri o formato da matriz. É visto na indústria de modelagem de plásticos e metais. Imagine uma bisnaga de um confeiteiro, onde sua ponta tem um formato de uma estrela, consequentemente o conteúdo extraído dela terá o mesmo formato. $\mathrm{Na}$ computação gráfica, uma cópia da forma bidimensional é estendida ao longo do eixo escolhido; o programa conecta as duas faces, obtendo um modelo tridimensional. Essa técnica é bastante utilizada quando se deseja projetar um objeto onde o seu contorno é de fácil reprodução no plano, observe a figura:

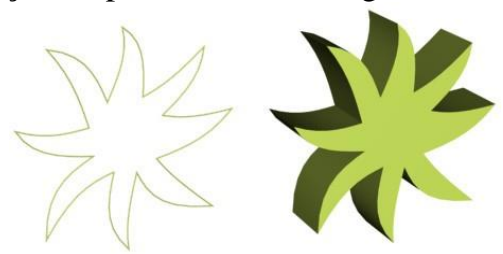

Figura 11 - Extrusão

Uma variante do conceito de extrusão, a Modelagem por Seç̧ão Transversal Serial, permite a conexão de diversas secções bidimensionais que podem ter diversas formas e tamanhos. Essa abordagem desvencilha o usuário do visual simétrico, permitindo a modelagem de formas naturais. As fatias são dispostas seguindo um caminho em linha reta ou curva na direção desejada, conhecidas também com linhas-guia ou auxiliares, observe a figura:

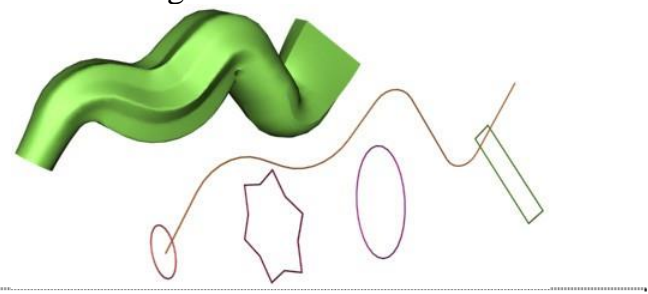

Figura 12 - Loft por linha-guia

Dispondo as fatias como camadas superpostas, pode-se obter a elevação irregular de superfícies, muito útil em topografia. Daí a origem do vocábulo em inglês lofting também usado para referência a esse procedimento. Usando fragmentos curvos para conexão das seções, um artista pode fazer ajustes pontuais no modelo (através de pontos de controle) para introdução de características plásticas individualizadas, nesse caso, ela já estaria fazendo uso de um método descrito anteriormente (modelagem de forma livre), dizemos isso para esclarecer que o artista pode lançar mão de todos os recursos oferecidos pelo sistema e trabalhá-los de forma integrada, desde que a geometria escolhida permita. Este processo é muito útil para a criação de formas orgânicas, como, por exemplo, seres humanos, uma vez que estas formas são facilmente descritas por uma série de contornos bidimensionais.

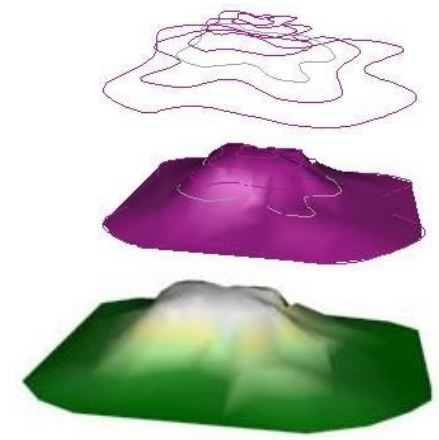

Figura 13 - Lofting

DAPesquisa, Florianópolis, v.2, n.4, p. 388-402, 2007. 
$\mathrm{Na}$ última técnica de modelagem por derivação, a de Revolução, o software realiza um giro completo em torno do próprio eixo de uma forma bidimensional, antes de autorizar o programa a proceder à operação, o usuário pode definir a proximidade do eixo de rotação em relação ao contorno de partida e ao número de subdivisões da forma resultante. Com isso obtêm-se formas sólidas ou vazadas, e curvas facetadas. Outras variações são possível como escolha do ângulo de rotação e quantidade de pontos ao desenhar o contorno de partida - esse último sendo importante quanto à decisão por usar polígonos ou fragmento curvo na geração do modelo 3D.

Levando-se em consideração a simplicidade de aplicação com obtenção de variadas e complexas formas tridimensionais, é uma das mais versáteis e poderosas ferramentas para modelagem digital. Seu equivalente no mundo real são a roda de oleiro e o torno mecânico, instrumentos que contribuíram decisivamente para moldar a cultura humana, fornecendo uma infinidade de utensílios e ornamentos ao longo da história com tal praticidade e regularidade, que teríamos aí a essência da produção em série.
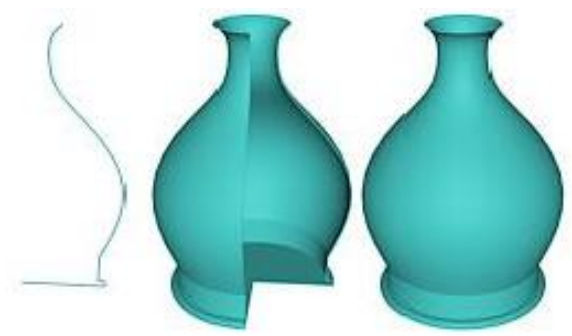

Figura 14 - Derivação por revolução

\subsubsection{Técnicas especiais de modelagens}

\subsubsection{Modelagem de Plantas}

Modelos tridimensionais de plantas e árvores criados com técnicas processuais que oferecem hoje uma série de controles, tornando assim uma modelagem fácil e mais eficiente que a maioria das outras técnicas. Devese ao grande número de elementos e detalhamentos contidos na superfície de uma planta, como também a complexidade de formas.

Modelos de plantas podem ser construídos codificando suas características em umas séries de regras ou procedimentos que são usado como a base para uma simulação de crescimento. Este método também pode ser usado para animar o processo de crescimento de modelos de planta em uma cena. Há vários modos para gerar modelos de plantas com técnicas processuais. Estas técnicas segundo Kerlow(2000), podem ser classificadas como: espaçoorientado ou estrutura-orientada.

A técnica processual de espaço-orientado é referese à modelagem das plantas e a animação do seu crescimento baseado no efeito do ambiente onde estão inseridas. Por outro lado, a técnica de estruturaorientada baseia-se nas condições internas da planta, mais especificamente o processo crescente da planta e a estrutura resultante que são características das espécies das plantas.

Muitas das técnicas de modelagem processuais voltados ao processo de crescimento de plantas, são freqüentemente expressos nos termos dos modelos matemáticos formalizados pelo biólogo Aristide Lindenmayer durante a década de 1960. Estes modelos de estrutura-orientada descrevem o processo de crescimento de plantas ao nível de interação celular e são conhecido como L-Systems. Utiliza-se o L-Systems especialmente para representar estruturas que se ramificam paralelamente, ou seja, como as divisões de um tronco de árvore que subdividem-se em vários galhos ao mesmo tempo, observe a figura:

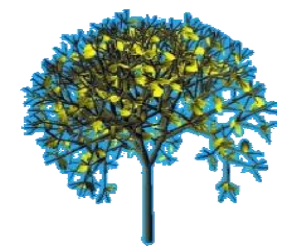

Figura 15 - Modelagem de planta - "L-Systems"

Outra característica dos L-systems está ligada ao ciclo de ramificação das plantas, os procedimentos de ramificação geram módulos sucessivos que substituem os módulos antecedentes.

Há muitas variações dos L-Systems, alguns estão ligados aos parâmetros que representam condições exclusivas, como o florescer das plantas.

\subsubsection{Modelagens por Simulações Físicas}

Segundo Kerlow(2000), o modo mais fácil para modelar materiais naturais cuja forma está em mudança constante é não os esculpir mas simular sua existência. Simulações físicas são muito utilizadas para modelar fenômenos naturais como chuva, fogo, fumaça e até mesmo vento.

Algumas dessas técnicas permitem os profissionais animarem ondas com também controlar variáveis como: altura da onda, declive, direção, freqüência, e velocidade. Outras colocações globais determinam à complexidade das ondas, seus padrões, como também seus movimentos subaquáticos.

Os parâmetros de sombra em uma simulação física de água podem incluir variáveis como brilho, mapas de relevo de superfície, reflexos obscuros e índice de refração. Profundidade e visibilidade nebulosas são freqüentemente usadas em cenas subaquáticas.

A transformação de objetos sólidos em objetos flexíveis, como por exemplo tecido, também podem ser

DAPesquisa, Florianópolis, v.2, n.4, p. 388-402, 2007. 
controlados por simulações físicas, onde pode-se controlar simulações de gravidade, observe os exemplos:
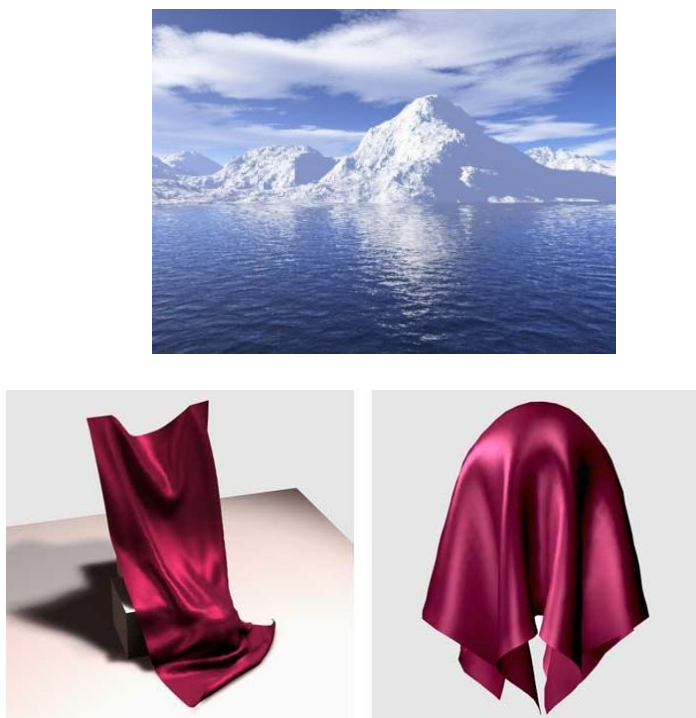

Figura 16-Modelagens por simulações físicas

\subsubsection{Modelagem baseada em Fotogrametria}

Técnicas de fotogrametria nos permitem reconstruir ambientes 3-D extraindo a informação tridimensional de umas séries de fotografias de locais mapeados. O processo de reconstrução nos programas de fotogrametria começa indicando nas fotografias feitas à varredura dos cantos ou bordas principais. Programas de fotogrametria reconstroem uma versão simples da geometria, analisando e comparando sua perspectiva e obscurecendo informações de várias imagens relacionadas do mesmo ambiente. Outra técnica que pode ser muito efetiva para modelar ambientes tridimensionais grandes, é o esquadrinhamento a laser. Esta técnica usa freqüentemente um scanner de laser linear para capturar dados de ponto tridimensionais que são convertidos então em uma malha poligonal. Um uso interessante desta técnica é a junção do filme tradicional ou filmadoras para capturar mapas de imagem de altaresolução que podem ser aplicados à geometria, observe a imagem abaixo:

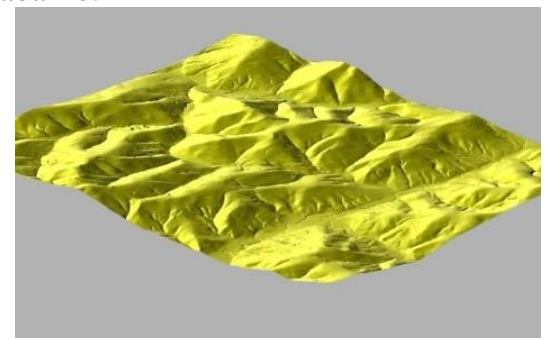

Figura 17 - Modelagem por fotogrametria

\section{Iluminação}

Falar de iluminação de superfície 3D implica tratar do processo de renderização ${ }^{10}$ da imagem. Mas embora o render não envolva somente o cálculo do efeito de luz inclui desde a disposição dos elementos da cena, a eliminação de linhas e superfícies ocultas, transformação perspectiva, até chegar à apresentação final da imagem numa grade de pixels -, é a modelagem através da simulação da luminosidade que garante a aparência realista no ambiente virtual.

Aliás, isso não é de estranhar, pois a luz exerce esse mesmo papel no mundo real, permitindo a evidência das cores e sombras, que, afinal, dão visibilidade às coisas. geométricos, usando cores e sombras para que tenha um toque realista. O rendering é um recurso habitual dos softwares de modelagem geométrica, como os programas de $\mathrm{CAD}$, que utilizam elementos matemáticos para descrever a posição de uma fonte de luz com relação ao objeto e para calcular o modo como a luz produziria pontos de maior brilho, sombreados e variações de cor. Assim é possível fazer com que polígonos opacos e sombreados se transformem em imagens bastante próximas de fotografias pela sua complexidade. Fonte: Dicionário Digital NETPÉDIA

Vemos graças à presença ou ausência relativa de luz, cuja variação permiti distinguir a complexidade da informação visual do ambiente.

Já no desenho e na pintura com materiais tradicionais, a aplicação de gradações tonais e matizes de cor são responsáveis pela ilusão do volume e representação realista. Se compararmos um desenho corretamente esboçado em perspectiva com uma pintura pré-renascentista, como por exemplo, algum trabalho de Giotto, que ainda não fazia uso apropriado desse recurso de simulação da profundidade no plano, veremos que, mesmo assim, é a pintura que transmite mais veracidade visual. A luz parece torná-la mais substanciosa. Não foi à toa que o próprio Leonardo da Vinci desenvolveu a técnica do "claro-escuro" e "esfumaçado", proporcionando um toque realista definitivo para a pintura, estas técnicas podem ser observadas em um dos seus melhores trabalhos, "Mona Lisa (1503)", onde o esfumado é caracterizado por uma transição sutil entre as cores; o claro-escuro é a técnica de definir formas através de contrastes de luz e sombra.

${ }^{10}$ Renderização é a criação de uma imagem contendo modelos geométricos, usando cores e sombras para que tenha um toque realista. O rendering é um recurso habitual dos softwares de modelagem geométrica, como os programas de $\mathrm{CAD}$, que utilizam elementos matemáticos para descrever a posição de uma fonte de luz com relação ao objeto e para calcular o modo como a luz produziria pontos de maior brilho, sombreados e variações de cor. Assim é possível fazer com que polígonos opacos e sombreados se transformem em imagens bastante próximas de fotografias pela sua complexidade. Fonte: Dicionário Digital NETPÉDIA

DAPesquisa, Florianópolis, v.2, n.4, p. 388-402, 2007. 


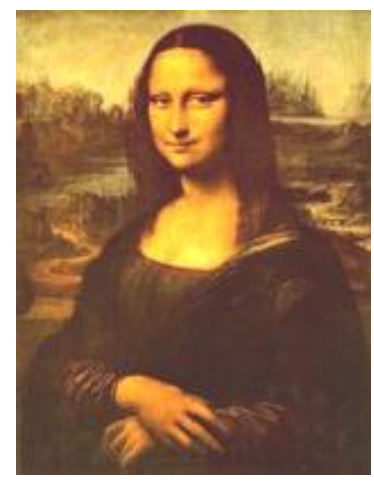

Figura 18 - Mona Lisa

Fonte:http://www.thedavincigame.com/Resources/Mona_Lisa _Da_Vinci_Painting.JPG

Na computação gráfica, coube mais uma vez à Universidade de Utah o privilégio de oferecer os dois modelos de iluminação que, no começo da década de 1970, fizeram acreditar na possibilidade da ilusão fotorrealista na síntese da imagem digital, apresentando objetos com aparência de superfície sólida e contínua.

$\mathrm{O}$ primeiro modelo com eficiência computacional a apresentar uma superfície suavemente iluminada foi proposto por Henri Gouraud em 1971. O método aplica um modelo de iluminação em um subconjunto de pontos de superfície e interpola a intensidade dos pontos restantes na superfície.

No caso de uma malha poligonal o modelo de iluminação é aplicado a cada vértice e as cores no interior dos triângulos são linearmente interpoladas dos valores dos vértices.

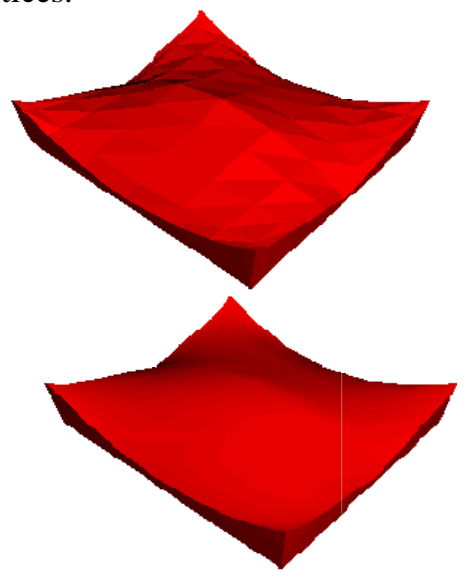

Figura 19-Método de Gourard

Apesar da superioridade alcançada pelo modelo de iluminação de Gourard ainda se tinha um problema, o algoritmo proposto tratava qualquer superfície de maneira uniforme, refletindo a luz por igual, fazendo com que os objetos ficassem opacos. Mạis tarde, em 1975, Bui Tuong Phong criou uma técnica que calcula as normais nos vértices, e interpola as normais para

DAPesquisa, Florianópolis, v.2, n.4, p. 388-402, 2007. calcular o modelo de iluminação em cada pixel do polígono, esta técnica apresenta os melhores resultados para superfícies especulares, ou seja, ela incorpora brilho a superfícies dos objetos, mas também exige um maior cálculo de processamento da CPU.

Se compararmos as duas técnicas, a de Gouraud e a desenvolvida por Phong, pode-se afirmar que a técnica utilizada por Phong calcula a tonalidade de cada ponto na superfície, o que torna um melhor acabamento na renderização do objeto.
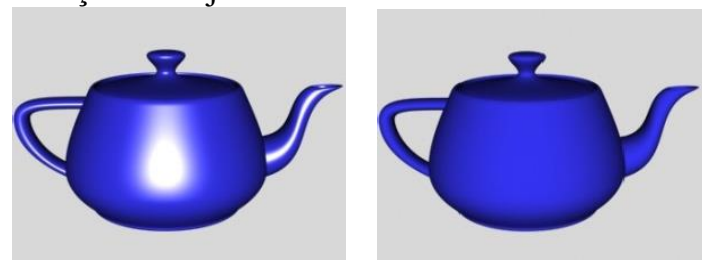

Figura 20 - Técnica de Phong e Gouraud

As pesquisas desenvolvidas pela Universidade de Utah representavam as principais pesquisas na área de computação gráfica. No caso da computação gráfica, no que diz respeito aos modelos de iluminação, segundo Barbosa Júnior (2002), a comunidade científica não levou a sério a técnica desenvolvida pelo grupo Phillip Mittelman, na Mathematical Applications Group Inc. Quando a MAGI começou, em meados de 1960, havia desenvolvido um sistema inicialmente para o governo americano, chamado "transporte de radiação nuclear", o qual tinha o propósito de que na existência de um reator nuclear, quanta radiação sairia e que tipo de dose de radiação adquiririam as pessoas.

Ainda segundo Barbosa Júnior (2002), especificamente o sistema desenvolvido descrevia três objetos dimensionais e então fazia com que esses objetos seguissem ao redor da radiação nuclear através de um caminho. Um dia foi percebido que, seguindo os raios claros em vez de radiação nuclear, poder-se-ia simular uma fotografia, onde foram simulados o caminho dos raios do sol para o objeto e do objeto pela lente de uma máquina fotográfica e consequientemente para o filme. Segundo Mittelman "se nós pudéssemos calcular a partir de tonalidades cada ponto no filme, nós poderíamos fazer uma fotografia de coisas .

Incorporado a esses estudos o grupo desenvolveu um programa para criar filmes no computador. Eles acrescentaram cor e outros refinamentos ao software, e em 1972, MAGI SynthaVision apresentou o processo para o mundo de propaganda. O programa foi refinado durante os anos, mas ainda é sem igual na indústria. Em lugar de usar só polígonos como o ponto de começo para a animação, MAGI SynthaVision utiliza combinações de outros tipos de formas para descrever objetos e trazer textura e contornos à superfície. Em 1975, um animador de Boston estava presente a uma apresentação administrada por Phillip Mittelman dos gráficos de computador que a companhia dele tinha estado criando para os anunciantes e outros clientes. $\mathrm{O}$ 
diretor de Tron, filme produzido em 1982 pelos estúdios Disney, Steven Lisberger, ficou fascinado com a possibilidade do computador criar perspectivas em ambientes tridimensionais, tornando assim, imagens mais reais.

O método do traçado de raios (raytracing) iria se mostrar o mais adequado para simular efeitos de brilho e transmissão da luz entre superfícies de modelos 3D. Só a partir do filme Tron, a comunidade científica reconheceu o mérito dessa abordagem - ainda assim, devido ao aval de outro pesquisador, Turner Whitted, que se voltou para o aprimoramento da técnica. Em 1980, Whitted incrementa a técnica considerada como Ray Tracing recursivo, que chamou de "An Improved Illumination Model for Shaded Display", com a aprimoramento da técnica Whitted mostrou como computar um modelo de iluminação aproximado, acompanhando os raios de luz que chegam ao olho no sentido inverso chamado de (Backward Ray Tracing).

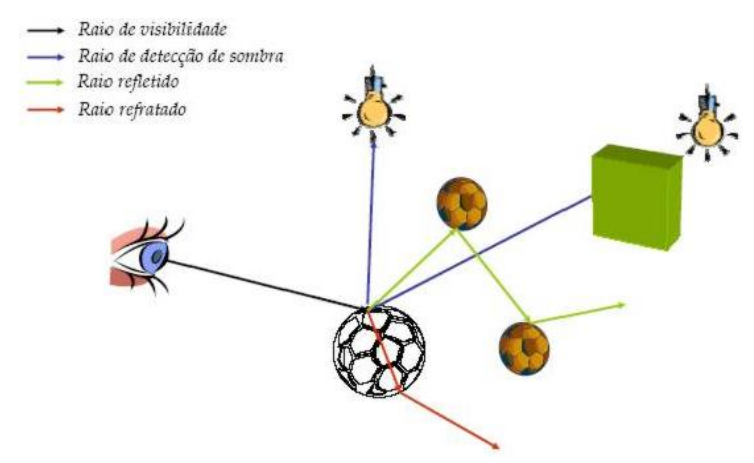

Figura $21-$ Ray tracing recursivo

\subsection{Tipos de Luzes}

\subsubsection{Luz branca}

Acredita-se, incorretamente, que a luz natural e a maioria das luzes artificiais são brancas. Mas a iluminação que elas produzem, na realidade, quase nunca são brancas. As luzes normalmente são tingidas. Poucos elementos na natureza, talvez a água possua um croma dinâmico como a luz, observe a figura 19.

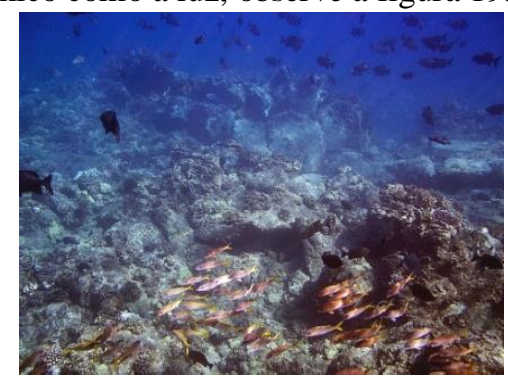

Figura 22 - Luz sobre a água

DAPesquisa, Florianópolis, v.2, n.4, p. 388-402, 2007.
A cor da luz muda com a hora, o tempo, a paisagem, e a posição na terra. Imaginando as diferenças cromáticas, por exemplo, entre a luz de uma tarde de inverno ensolarada nos países nórdicos ou um pôr-dosol de verão no Caribe tempestuoso, ou ainda, o sol do meio-dia nos céus limpos primavera do deserto rochoso australiano. A luz do inverno nórdica poderia ter um matiz azul leve, enquanto a luz de um pôr-do-sol caribenho tempestuoso poderia ter a cor rosa e a luz da primavera do deserto australiano poderia ter um matiz amarelo leve. A cor diferenciada nos três exemplos acima poderia ser sutil, mas muito significante se a pessoa está tentando simular ambientes como esses em um programa tridimensional.

\subsubsection{Luz colorida}

O efeito visual que as luzes coloridas produzem é grande, porém, elas devem ser usadas com prudência, especialmente quando se deseja iluminar espaços ou situações como, por exemplo, um ambiente festivo.

Outro exemplo interessante quando se utilizam luzes coloridas é quando são utilizadas em cenas de espetáculos (shows), comum em espetáculos de circo, onde são utilizadas luzes coloridas sobrepostas umas as outras. Este recurso de iluminação deve-se às cores inesperadas que são resultantes dessas combinações.

\subsubsection{Tipos de Fontes luminosas}

Segundo Kerlow(2000), há tipos básicos de fontes luminosas, de acordo com o modo no qual eles irradiam luz. Os tipos de fontes de iluminação simuladas são: ponto de luzes: luzes spot, lineares, de iluminação de áreas(regiões), luzes infinitas e luzes ambientes. Todos estes tipos de luz podem ser criadas e podem ser modificados pelo usuário. Além disso, a maioria dos softwares tridimensionais criam automaticamente uma ou várias luzes padrões em uma cena. Normalmente, esses esquemas padrões de iluminação podem ser personalizados e pode consistir em uma fonte de luz ambiente, uma luz infinita que simula a intensidade $\mathrm{e}$ posição do sol, ou um ponto de luz colocado atrás da câmera ou em qualquer outra posição dos eixos XYZ. Algumas luzes ditas como "default", ou seja, padrões pré-definidos pelo software, são "desligadas" automaticamente assim que o usuário cria uma fonte luminosa na cena.

\subsubsection{Luz do tipo ponto}

As luzes do tipo ponto, ou "point light", iluminam uniformemente em todas as direções. Por isto uma luz de ponto também é chamada omnidirectional, ou seja, em todas as direções, observe o exemplo: 


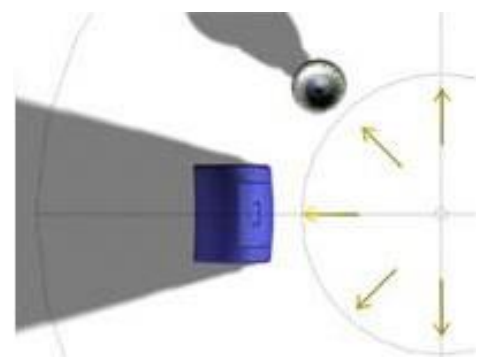

Figura 23-Luz Omni

Fonte: Help do software 3D studio max

A luze de ponto é o tipo mais comum em se tratando de fontes luminosas e elas podem ser colocados em qualquer lugar na cena. Por exemplo, podem ser colocadas luzes de ponto fora do campo de visão da câmera, atrás de um objeto na cena, ou até mesmo dentro de objetos. Os efeitos de luzes de ponto colocados dentro de objetos variam entre os softwares, mas em alguns casos a luz brilhará através da malha de um objeto transparente, como no caso de uma lâmpada incandescente. Uma lâmpada incandescente é um exemplo simples de uma luz de ponto. Uma estrela, uma vela, e um vaga-lume também são luzes de ponto mas requerem efeitos adicionais.

\subsubsection{Luz spot}

As luzes spot são semelhantes às omni's, mas possuem a forma de um cone e sua iluminação é feita somente em uma direção específica. Esse tipo de luz possui características muito específicas: um cone de luz onde pode ser ajustado seu ângulo e um fator de degradação da luz, observe a imagem abaixo:
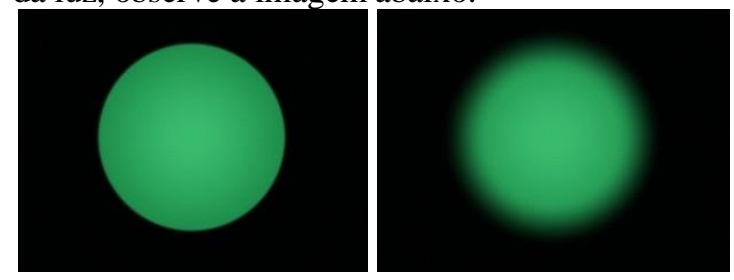

Figura 24 - Degradação da Luz

Lanternas, lâmpadas com sombras, abajures e refletores usados em ensaios fotográficos ou produções de filme são exemplos de luzes de ponto.

Esse tipo de luz é utilizado quando se deseja chamar a atenção do público em uma área específica da cena.

\subsubsection{Luz infinita}

Luzes infinitas são colocadas longe dos elementos que compõem a cena, apenas seus raios claros devem atingir os seus elementos. Também podem ser chamadas de luzes direcionais e elas se comportam como estrelas no céu. Mas ao contrário das estrelas, as luzes infinitas criadas por simulações computacionais podem ser colocadas em qualquer lugar no ambiente, são menos densas e sua intensidade pode ser modulada. Em alguns softwares as luzes infinitas têm uma intensidade constante, e não deterioram enquanto percorrem o espaço. O sol é um exemplo típico de uma fonte luminosa infinita que possa exatamente ser colocada com precisão sobre a cena, onde se informa a latitude e a longitude do local mais o tempo exato do dia e data, quando a cena estiver acontecendo, observe a imagem de exemplo:

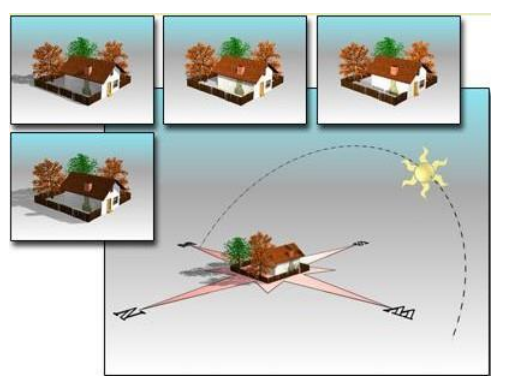

Figura 25-Luz infinita, posicionamento e efeito. Fonte: Help do software 3D studio max

\subsubsection{Luz de área}

Alguns programas provêem luzes de área na forma de luzes múltiplas ou uma única área grande de luz, podem ser escolhidas luzes de área de qualquer tamanho, mas elas podem ser mais eficientes quando não são muito grandes, elas possuem geralmente formas retangulares ou circulares.

As luzes de área são especialmente úteis quando se deseja iluminar áreas pequenas uniformemente, também podem ser usadas para simular a reflexão de uma luz que entra em um ambiente através de suas janelas.

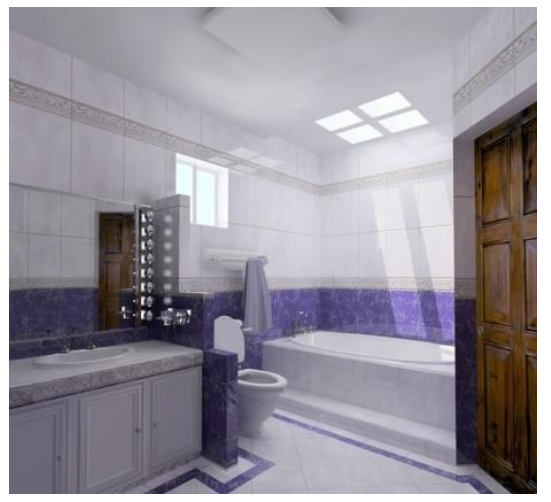

Figura 26 - Luz de área

DAPesquisa, Florianópolis, v.2, n.4, p. 388-402, 2007. 


\subsubsection{Luz linear}

A luz dos tubos fluorescentes podem ser melhores simuladas com luzes lineares. Luzes lineares possuem comprimento, mas não largura, e elas também podem ser criadas de qualquer tamanho. $\mathrm{O}$ uso das fontes luminosas lineares devem ser exercitadas com muito cuidado, porque sua renderização em alguns casos pode ser muito mais demorada que a combinação de várias luzes de ponto.

\subsubsection{Luz ambiente}

A luz emitida pela fonte luminosa ambiente é distribuída uniformemente ao longo da cena inteira.

$\mathrm{O}$ termo luz ambiente é freqüentemente usado por alguns softwares tridimensionais, e tecnicamente falando, nem sempre refere-se a uma fonte de luz ambiente. Em alguns casos utiliza-se uma fonte luminosa de ponto que é criada automaticamente pelo programa para cada cena.

Embora a luz ambiente possa ser colocada em uma posição específica nas coordenadas XYZ, dentro de um ambiente tridimensional, imagine uma luz ambiente que emita seus raios em todas as direções. A luz ambiente determina o nível geral de iluminação ou a sombra de uma cena e geralmente utiliza-se somente uma luz ambiente por cena.

\section{Textura}

As texturas geradas em computação gráfica podem ser consideradas contribuições decisivas para se conseguir a ilusão do real na computação gráfica, advento que ficou conhecido como o mapeamento de textura. Pode-se dizer que ainda estamos submergidos pela área da iluminação, mas as particularidades desse tópico sugerem que devemos considerá-lo de forma independente.

As técnicas de mapeamento de texturas se desenvolveram como possibilidade de subdivisão recursiva de fragmentos propostas por Edwin Catrmull, que requeria a correspondência entre pontos na superfície do fragmento com os pixels da matriz de exibição, associando aos pixels informação dos valores de iluminação de cada ponto. Agregando dados de luminosidade referentes a uma imagem do tipo bitmap a esses pixels, o fragmento de superfície exibiria a textura dessa imagem, como seus brilhos, cores e padrões.

Os objetos mapeados, no entanto, ainda apresentavam uma superfície invariavelmente plana, suave, comprometendo a percepção de suas características materiais. Sem falar que, muitos objetos refletem, na própria superfície (em maior ou menor grau), o ambiente ao seu redor. Acrescentar ao mapeamento de texturas essas particularidades foi uma das últimas grandes contribuições da Universidade de

DAPesquisa, Florianópolis, v.2, n.4, p. 388-402, 2007.
Utah à computação gráfica, ocorrida em meados da década de 70.

As principais idéias partiram de um artigo publicado em 1976 pela parceria de James Blinn e Martin Newell, o referente artigo descrevia uma continuidade do algoritmo desenvolvido por Edwin Catmull aplicados em simulações de texturas em modelos iluminados. A proposta de Blinn e Newell foi desenvolver um algoritmo que auxiliado por um controle preciso que as quatro coordenadas que definem o minúsculo fragmento bicúbico ofereciam, permitindo o estabelecimento de quatro normais para cada pixel, que garantiam a orientação tridimensional exata. Uma espécie de "espaço paralelo" é introduzido para ser usado em conjunto com as coordenadas do espaço tridimensional do objeto. Esse espaço alternativo, chamado de paramétrico, recebe as coordenadas $u$ (valores horizontais) e $v$ (valores verticais), contendo os padrões da imagem usada no mapeamento, equivalentes quanto às características geométricas e luminosas do fragmento bicúbico. Isso possibilitou uma ampla manipulação do espaço paramétrico contendo os dados de textura (inclinar, esticar e torcer), que são projetados nos espaços correspondidos as coordenadas $(u, v$ com os eixos $x, y)$.

Mudando os parâmetros de cada ponto do mapa da imagem, alteram-se cores e intensidade. Mudando os valores do objeto no qual a textura é aplicada, essa reflete a variação, graças à vinculação entre pixels e fragmentos da superfície do objeto.

Esses procedimentos de enorme impacto na computação gráfica traziam para o mundo digital princípios há séculos empregados pelos pintores para obtenção de efeitos visuais. Os artistas alteravam suas imagens trabalhando com conceitos geométricos a partir de planos acrescentados ao desenho original. A imagem tinha seu modelo equivalente devidamente mapeado com quadrículas (os pixels da matriz digital), que eram submetidas a distorções perspectivas de toda ordem. $\mathrm{O}$ principal objetivo dessas transformações era tanto ajustar o rigor linear à natural deformação típica da nossa fisiologia óptica, como os estudos de Piero della Francesca e Leonardo da Vinci que levaram ao conceito da perspectiva curvilínea, como explorar o inusitado através do exagero formal, como da op art ${ }^{11}$ e na obra de M. C. Escher).

\footnotetext{
${ }^{11}$ Op Art é a forma abreviada de Optical Art, expressão inglesa que designa um movimento ou tendência iniciada na Europa e logo propagada aos Estados Unidos em começos da década de 1960.
} 


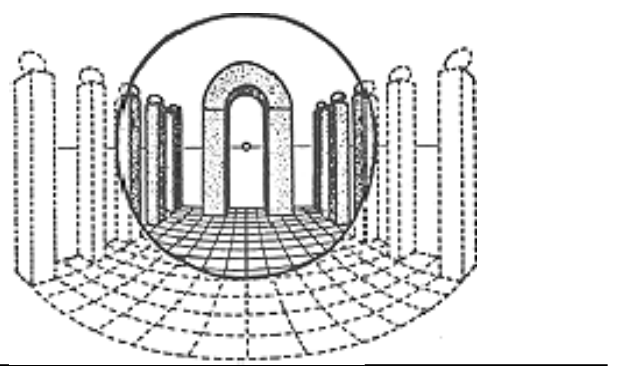

Figura 27 - Perspectiva curvilínea

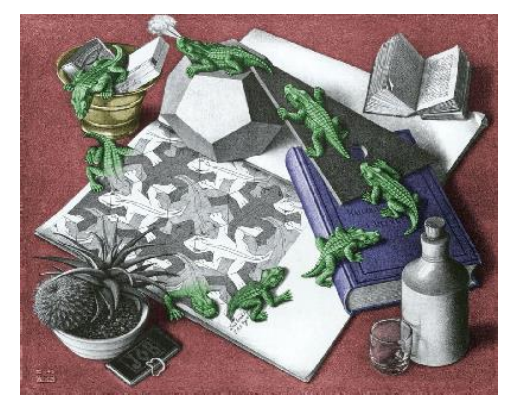

Figura 28 - "Répteis", trabalho de E.C. Escher (optical art)

Fonte: http://www.etropolis.com/escher/reptiles.htm

Com base nas idéias que levaram o plano paramétrico, surgem os importantes algoritmos que permitiram simular a rugosidade das texturas (bump mapping), a simulação do ambiente circundante (environment mapping) e o efeito de substâncias nebulosas, névoa por dispersão de partículas (particle scatting). O efeito de bump mapping cria a ilusão de rugosidade na superfície dos objetos apenas alterando a direção com que os raios de luz são refletidos, sem alterar a geometria do modelo.

Não é por outro motivo que o processo de formação de cor por pigmentação (em detrimento dos processos aditivos e subtrativos) seria o mais adequado modelo matemático a ser representado no computador, para utilização nos sistemas de pintura digital.

James Blinn reproduziu essa característica elaborando um algoritmo que ocasionava um desarranjo nas normais do fragmento, partindo dos valores do mapa da textura empregado, efetivamente perturbando a simetria desses valores, cuja ordem era responsável pela aparência lisa da superfície, parecendo um plástico.

Em termos práticos, um padrão mapeado, ou seja, acoplado ao objeto, apresentaria depressão nas áreas escuras e protuberância nas áreas claras tangentes à superfície do modelo, ou vice-versa. As tonalidades intermediárias de cinza recebem mais ou menos cavidade ou saliência, dependendo de quão mais escuro ou mais claro seja o tom de cinza.

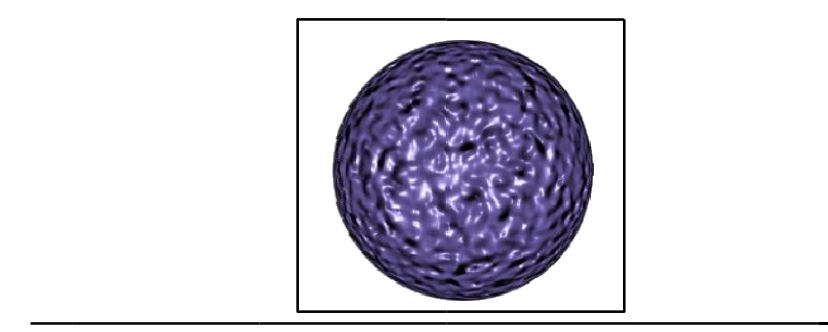

Figura 29-Mapa bump

No mapeamento do ambiente (environment mapping), o ponto de partida foi imaginar o objeto envolvido por uma grande esfera, seu universo circundante, cuja superfície interna representava uma imagem do ambiente em torno do objeto como sendo "visto" pelo próprio objeto. Essa versão bidimensional do ambiente continha informações corretas do ângulo de reflexão e intensidade dos raios, convertidas num sistema de coordenadas polares correspondendo aos eixos $x, y$.

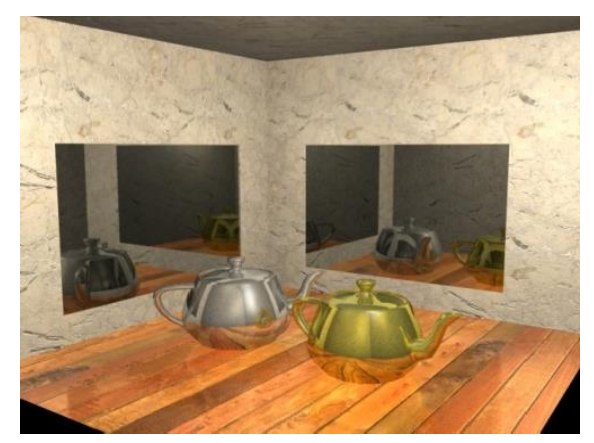

Figura 30 - Environment mapping

Já a simulação de efeito atmosférico (fog, névoa) é outra técnica que possui referência na pintura tradicional, Leonardo da Vinci, no século XV,

desenvolveu a perspectiva atmosférica como complemento ao traçado linear, no intuito de reforçar a sensação de profundidade e realismo pela interferência de elementos que afetam a luminosidade do espaço. Isso era feito sobrepondo-se camadas de tintas transparente, com pouca pigmentação (partículas de tinta), por meio de uma técnica conhecida por veladura. No modelo de Blinn, esse efeito é representado dispondo-se uma infinidade de partículas (esferas minúsculas), aleatoriamente distribuídas no espaço, com as propriedades de absorver e refletir luz em qualquer direção. Quanto mais densa a nuvem de partículas, menores as chances da luz atingir o observador. 


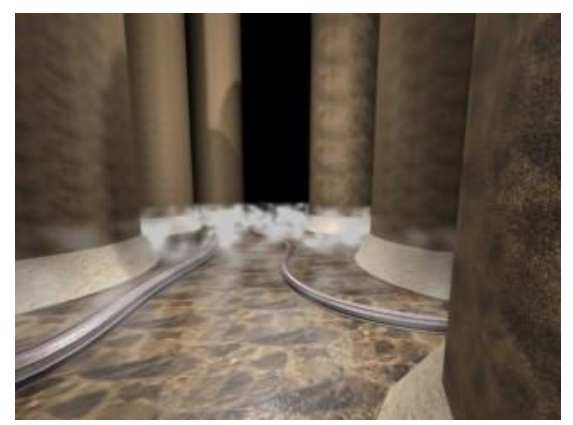

Figura 31 - Efeito Fog

Com essas invenções, a síntese de imagem digital completava o ciclo das tecnologias fundamentais para a criação de imagem por processos computacionais empregada por pacotes gráficos 3D comercializados nas de 1980-1990, quando só então esses recursos iniciam a transformação do paradigma na elaboração visual, e, basicamente quando empunhados por artistas de sólida formação ortodoxa.

\section{Renderização}

A maioria das características visuais de um ambiente tridimensional são determinadas durante o processo de renderização, é nele que são geradas as imagens finais de todos os efeitos aplicados à cena.

$\mathrm{O}$ processo global de renderização segundo Kerlow(2000), consiste em cinco etapas principais que são utilizados nos sistemas computacionais. Não é necessário que estes passos aconteçam em uma ordem rígida.

O primeiro passo no processo de renderização consiste em fazer com que seja carregado o arquivo de algum periférico de armazenamento, como por exemplo, um disco rígido, para que as técnicas utilizadas na cena possam ser interpretadas, estas técnicas podem ser: características, propriedades e ajustes.

Após carregarmos o arquivo, o segundo passo é manipulada a câmera entre as coordenadas XYZ, de forma que se consiga a imagem ideal da cena. Nós podemos reposicionar a câmera, inclinar, mudar o seu foco e a profundidade do campo de visão, como também, ajustar as proporções e a resolução da imagem. Se necessário, podemos futuramente rearranjar os objetos da cena. Após fazer estes ajustes, no terceiro passo é verificado e implementado o esquema de iluminação. Isto pode ser feito alterando o posicionamento das luzes e suas características.

No quarto passo especificamos as características das superfícies dos objetos, inclusive sua cor, textura, brilho, reflexo e transparência. As características de superfície requerem bastante atenção nos seus detalhes. Obtendo-se um bom resultado durante esta fase, teremos um grande impacto na sua qualidade e no refinamento do resultado final.
Finalmente, o quinto passo consiste em escolher um método de matização e gerar a imagem final. Especificar as características de superfície e escolher as técnicas de matização são dois passos distintos, mas eles estão intrinsecamente relacionados e freqüentemente sobrepõem-se entre si.

Quando a geometria ou matização de uma determinada cena são muito complexas é comum que se renderizem os componentes diferentes da cena separadamente. Isto normalmente é chamado renderização por camadas. Um exemplo simples deste método consistiria por si só na renderização com o fundo, renderizando apenas os elementos de primeiro plano.

Em uma renderização podem ser utilizados vários métodos para se obter uma visão de "arame", ou seja, a malha dos objetos de um modelo tridimensional em uma imagem preenchida. Além da colocação pré-definida de fontes luminosas em uma cena e a tarefa de características de superfície para objetos, a imagem sombreada final depende do método de renderização utilizado. É importante colocar que os usuários desses ambientes são dependentes dos métodos de renderização, ou algoritmos utilizados. Isto acontece porque a maioria desses métodos normalmente são fornecidos como "caixas pretas" que só aceitam dados de geometria e variáveis de renderização como: luzes, sombras e as características de superfícies.

Alguns programas de renderização provêem notas técnicas extensas que explicam como eles trabalham, e tal nota pode prover perspicácias úteis sobre os modos nos quais o programa trabalha. Estas informações podem ser inestimáveis na montagem de uma cena. $\mathrm{Na}$ maioria dos casos o usuário deve praticar algumas horas de trabalho para compreender como um determinado software de renderização trabalha. Conhecendo as características de um sistema de renderização fica mais fácil para que se consiga alcançar um melhor resultado no trabalho final.

\section{Resultados}

O presente trabalho estudou alguns softwares de modelagem tridimensional, bem como seus métodos de renderização, o estudo desses softwares permitiu com que fossem observadas várias etapas que envolvem todos os processos da construção de uma cena final, ou seja, suas técnicas de modelagens, texturizações, iluminação, posicionamento de câmera e geração de sombras.

Os resultados obtidos a partir desse estudo foi que quase todos os softwares são baseados nas mesmas técnicas para a construção de uma cena, diferenciandose apenas na ordem desses passos, uns mais interativos que outros, mas basicamente utilizam a mesma lógica de scripts de programação, a diferenças entre os softwares estudados é de que o CAD possue uma

DAPesquisa, Florianópolis, v.2, n.4, p. 388-402, 2007. 
preocupação maior no quesito precisão, fazendo com que várias etapas da modelagem fiquem muito mais rígidas em comparação com o software 3D Studio Max por exemplo, que por ser um software ilustrativo, possui uma flexibilidade maior na modelagem de objetos, mas em contraponto, é muito real quando se trata da renderização de uma cena. O ponto mais interessante que se pôde observar no estudo desses softwares é que eles estão chegando a uma perfeição muito grande na geração de imagens reais, constatou-se que todos eles possuem processos que fazem com que se possam gerar simulações atmosféricas reais, como: gravidade, vento e outros.

O resultado dessa pesquisa foi extremamente compensador, pois possibilitou a identificação de suas ferramentas, a maneira que cada uma comporta-se e a comparação das mesmas nos outros softwares estudados.

\section{Discussão}

Apesar da tecnologia envolvida no processo da modelagem tridimensional estar em constante processo de aprimoramento, considerando todas as ferramentas que hoje se encontram a disposição do profissional, como os supercomputadores e os softwares tridimensionais, bem como, suas ferramentas de renderização. Pode-se observar que hoje, com a tecnologia existente, podem-se obter excelentes resultados, como também criar simulações reais que auxiliam em diversas áreas profissionais, um exemplo claro disso é no desenvolvimento de produtos, onde o cliente pode ver o produto mesmo antes de sua construção, de forma virtual.

Outra característica observada são as simulações de teste de resistência, movimentos de motores, funcionamento de molas e outros, que foram incorporados no software SolidWorks.

\section{Conclusão}

O presente trabalho verificou que o processo de modelagem tridimensional, para que se chegue ao resultado final, são envolvidas várias etapas, e que como pôde ser observado é que cada uma delas é importantíssima para que se possam alcançar os resultados esperados.

Pôde-se observar também, que os softwares tridimensionais estão, a cada atualização, gerando imagens mais semelhantes aos ambientes reais, e que se podem criar várias simulações através desses softwares, um exemplo que caracteriza bem, são os ambientes que utilizam iluminações complexas. Com o avanço dos softwares de renderização, essas luzes podem gerar ambientes muito semelhantes com espaços reais, vários cenas criadas nesses softwares, são muitas vezes confundidas com fotografias reais, o que pode ser observado na imagem abaixo.

DAPesquisa, Florianópolis, v.2, n.4, p. 388-402, 2007.

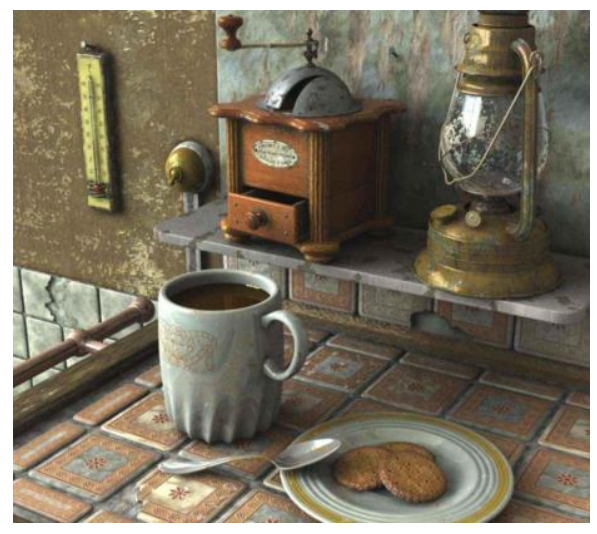

Figura 32 - Render Final, iluminação e texturas.

Com o exemplo mostrado, fica mais claro o entendimento de como os softwares, através de seus profissionais, possibilitam a geração de imagens bastante semelhantes com fotografias reais.

$O$ resultado de tal atividade, entretanto, ainda deve se adequar ao repertório de associações que o seu expectador é capaz de efetuar. Para tanto, é fundamental que o produto final de tal técnica siga princípios que o expectador tenha consagrado.

\section{Referências Bibliográficas}

BELL, Jon A.; Shafer, Robertson, Ken Allen; Spaw, Michael e Tumlin, Scot. Dominando o 3D Studio Max R3 - Efeitos Especiais e Design, Rio de Janeiro, Editora Ciência Moderna, 2000.

BARBOSA JÚNIOR, Alberto Lucena. Arte da animação. Técnica e estética através da história. São Paulo: Editora SENAC, 2002.

BLINN, James e NEWELL Martin. Texture and reflection in computer generated images. Disponível em: <http://portal.acm.org/citation.cfm?id=360353>. Acesso em 30 de maio de 2005.

BOARDMAN, Ted. Desvendando o 3D Studio Max 3 - Modelagem, Materiais e Renderização, São Paulo: Editora Campus, 1999.

BONNEY, Sean. 3ds Max 4 Efeitos Magicos, Rio de Janeiro: Editora Ciência Moderna, 2002.

CATMULL, Edwin Earl. on line: A Subdivision Algorithm for Computer Display of Curved Surfaces Disponível em: <http://wwwlib.umi.com/dissertations/preview_all/7504 786> Acesso em: 14 de março de 2005.

CERVO, A. L. Bervian, P. A. Metodologia científica.3. São Paulo: McGraw- Hill do Brasil, 1983. 
CLARK, H. James on line. Hierarchical Geometric Models for Visible Surface Algorithms. Disponível em: <http://accad.osu.edu/ waynec/history/PDFs/clarkvis-surface.pdf $>$ Acesso em: 09 de março de 2005.

\section{DICIONÁRIO ELETRÔNICO NETPÉDIA.}

Disponível em: 〈http://www.netpedia.com.br〉. Acesso em: 27 de maio de 2006.

KERLOW, Isaac Victor. The Art of 3-D : Computer Animation and Imaging. 2nd .ed. New York: John Wiley \& Sons, 2000.

NEWMAN, W. A. on line: A graphical technique for numerical input. Disponível em: <http://www3.oup.co.uk/computer_journal/hdb/Volume _11/Issue_01/110063.sgm.abs.html>. Acesso em: 09 março 2005 .

SANTOS, Eduardo Toledo. Avaliação do algoritmo de "ray traincing" em multicomputadores. Disponível em: <http://www.teses.usp.br/teses/disponiveis/3/3141/tde31032004-123720/publico/dissert-toledo.pdf $>$ Acesso em: 16 de maio de 2005.

WHITTED, T. An Improved Illumination Model for Shaded Display. Comm. of the ACM, v. 23, n.6, p. 343-349, 1980.

PETERSON, Michael. 3D Studio Max 3 Fundamentos, São Paulo: Editora Campus, 2000. 